\title{
miR-411 is up-regulated in FSHD myoblasts and suppresses myogenic factors
}

\author{
Naoe Harafuji ${ }^{1}$, Peter Schneiderat ${ }^{2}$, Maggie C Walter ${ }^{2}$ and Yi-Wen Chen ${ }^{1,3,4^{*}}$
}

\begin{abstract}
Background: Facioscapulohumeral muscular dystrophy (FSHD) is an autosomal dominant muscle disorder, which is linked to the contraction of the D4Z4 array at chromosome 4q35. Recent studies suggest that this shortening of the D4Z4 array leads to aberrant expression of double homeobox protein 4 (DUX4) and causes FSHD. In addition, misregulation of microRNAs (miRNAs) has been reported in muscular dystrophies including FSHD. In this study, we identified a miRNA that is differentially expressed in FSHD myoblasts and investigated its function.
\end{abstract}

Methods: To identify misregulated miRNAs and their potential targets in FSHD myoblasts, we performed expression profiling of both miRNA and mRNA using TaqMan Human MicroRNA Arrays and Affymetrix Human Genome U133A plus 2.0 microarrays, respectively. In addition, we over-expressed miR-411 in $C_{2} C_{12}$ cells to determine the effect of miR-411 on myogenic markers.

Results: Using miRNA and mRNA expression profiling, we identified 8 miRNAs and 1,502 transcripts that were differentially expressed in FSHD myoblasts during cell proliferation. One of the 8 differentially expressed miRNAs, miR-411, was validated by quantitative RT-PCR in both primary ( 2.1 fold, $p<0.01)$ and immortalized $(2.7$ fold, $p<0.01)$ myoblasts. In situ hybridization showed cytoplasmic localization of miR-411 in FSHD myoblasts. By analyzing both miRNA and mRNA data using Partek Genomics Suite, we identified 4 mRNAs potentially regulated by miR-411 including YY1 associated factor 2 (YAF2). The down-regulation of YAF2 in immortalized myoblasts was validated by immunoblotting ( -3.7 fold, $p<0.01) . C_{2} C_{12}$ cells were transfected with miR-411 to determine whether miR-411 affects YAF2 expression in myoblasts. The results showed that over-expression of miR-411 reduced YAF2 mRNA expression. In addition, expression of myogenic markers including Myod, myogenin, and myosin heavy chain 1 (Myh 1) were suppressed by miR-411.

Conclusions: The study demonstrated that miR-411 was differentially expressed in FSHD myoblasts and may play a role in regulating myogenesis.

Keywords: FSHD, microRNA, miR-411, YAF2, YY1, Myod, myogenin

\section{Background}

Facioscapulohumeral muscular dystrophy (FSHD) is an autosomal dominant myopathy with estimated prevalence of $1: 20,000[1,2]$. The age of onset is often in the second decade of life with nearly complete penetrance (95\%) by age 20 [3]. FSHD is characterized by progressive weakness of different muscle groups, often starting with the facial muscles, followed by the shoulder girdle

\footnotetext{
* Correspondence: ychen@childrensnational.org

${ }^{1}$ Center for Genetic Medicine Research, Children's Research Institute, Washington, DC, USA

${ }^{3}$ Department of Integrative Systems Biology and Department of Pediatrics, George Washington University, Washington, DC, USA

Full list of author information is available at the end of the article
}

muscles, and moving down to the hip girdle and the extremities [4-6]. Many patients also exhibit a marked leftright asymmetry in muscle involvement $[4,7,8]$. Patients can have additional symptoms such as severe inflammation in muscles, subclinical hearing loss, and peripheral retinal capillary abnormalities [9-11]. Genetic studies of FSHD have shown that the disease is associated with a deletion of the D4Z4 repeats in the $4 \mathrm{q} 35$ subtelomeric region. In individuals without FSHD, this region contains up to 150 copies of the D4Z4 repeats while patients with FSHD only have one to ten copies of the repeat $[4,6,12-16]$.

Each D4Z4 repeat contains a double homeobox protein 4 (DUX4) gene. Several DUX4 splice variants have 
been reported to be expressed in germ-line cells and myoblasts [17-19]. Although the function of DUX4 is not yet known, the full-length DUX4 transcript (fl-DUX4) has been shown to be cytotoxic in vivo and ex vivo when ectopically expressed [19-23]. Several studies suggested that p53-dependent cell death plays a major role in the cytotoxicity of DUX4 [23-25]. Recent studies have also shown that a combination of two genomic features is required to cause FSHD. First, the contraction of the D4Z4 repeats causes hypomethylation of the D4Z4 region, allowing DUX4 mRNA to be transcribed [21,26]. Second, an intact polyadenylation signal in the region distal to the D4Z4 array allows DUX4 transcripts from the last D4Z4 repeat to be polyadenylated and therefore stable for protein translation. This combination of events leads to the aberrant expression of DUX4 and the downstream molecular changes involved in FSHD [17,21,27]. The aberrant expression of DUX4 in FSHD has been proposed to inhibit myogenesis by suppressing Myod regulated pathways and inducing muscle atrophy pathways [20,24,28-33]. However, the regulatory relationship between DUX4 and these pathways is not clear. Currently no effective therapy for FSHD is available. Several pharmacological treatments such as corticosteroids, albuterol, creatine monohydrate, and anti-human myostatin antibody have been tested for their efficacy of treating FSHD, but none showed promising results [34].

MicroRNAs (miRNAs) are short ( 22 nucleotides) noncoding RNAs which regulate gene expression by interfering translation or promoting degradation of target mRNAs [35,36]. A mature miRNA is generated through several steps. First, a primary-miRNA (pri-RNA) is transcribed and then cleaved to form a pre-miRNA, which is a single hairpin-shaped stem-loop [37]. Subsequently, the pre-miRNA is exported to the cytoplasm and cleaved into a mature miRNA duplex by Dicer $[37,38]$. The functional strand is incorporated into the RNA-induced silencing complex (RISC) to form a miRNA-RISC complex [39,40]. In general, the miRNA-RISC complex will cleave the target mRNA when the target sequence is perfectly complementary to the miRNA sequence, or it will interfere with translation of the target mRNA when mismatches are present in the target sequence [40,41]. Many miRNAs are conserved between vertebrates and invertebrates and have been shown to share functions in various cellular processes including embryogenesis, organogenesis, apoptosis, cell cycle regulation and disease development, including muscle disorders [40-43]. Several miRNAs have been shown to play important roles in muscle differentiation, including the miR-1 and miR-133 families, miR-181, miR214, miR-24, miR-221 and miR-222 [44-51]. In additional to normal muscle growth and maintenance, miRNAs have also been shown to be differentially expressed in disease conditions [52-54]. A global miRNA expression profile of
10 muscle disorders was previously performed and showed that 185 out of the 428 miRNAs examined were differentially expressed in at least one of the 10 different muscle disorders [55]. Among the 185 miRNAs, 62 were up-regulated in FSHD while none was down-regulated. These findings suggest that miRNAs may play a critical role in FSHD, although the mechanisms involved have not been studied. MiR-411 belongs to the miR-379 family and is located in the miR-379/miR-656 cluster within the DLK-DIO3 region on human chromosome 14 [56]. The miR-379/miR-656 cluster is highly conserved in placental mammals [56]. In mouse brain, the expression of the miR379/miR-656 gene cluster is likely co-regulated by myocyte enhancing factor 2 (Mef2) and is involved in activity-dependent outgrowth of hyppocampal neurons [57]. The function of miR-411 in brain or other tissues is currently unknown. In this study we performed miRNA expression profiling using PCR-based miRNA arrays to identify miRNAs misregulated in FSHD myoblasts. We then used mRNA profiling to identify potential regulatory targets of miR-411, which was significantly upregulated in the miRNA profiling. We further examined the effects of over-expressing miR-411 in $\mathrm{C}_{2} \mathrm{C}_{12}$ myoblasts and its potential role in myogenesis.

\section{Methods}

\section{Cell culture and immunostaining}

Primary myoblasts were obtained from EuroBioBank (Dr. Schneiderat and Dr. Walter) (Additional file 1: Table S1). For expression profiling experiments, cells were cultured in collagen I-coated flasks with SkGM (Lonza) at $37^{\circ} \mathrm{C}, 5 \% \mathrm{CO}_{2}$. For in situ hybridization experiments, cells were seeded on poly-D-lysine/mouse laminin-coated coverslips (BD BioCoat, BD Biosciences).

$\mathrm{C}_{2} \mathrm{C}_{12}$ cells were purchased from ATCC and cultured in growth medium consisting of DMEM (Life Technologies) with $10 \%$ heat-inactivated fetal bovine serum (Sigma). Myotube differentiation was induced by culturing the cells in differentiation medium consisting of DMEM with $2 \%$ heat-inactivated horse serum (Sigma) at $37^{\circ} \mathrm{C}, 5 \% \mathrm{CO}_{2}$.

Immortalized human myoblasts were from the Boston Biomedical Research Institute and cultured as described in previously published protocol $[58,59]$. Briefly, immortalized myoblasts were cultured in a growth medium consisting of medium 199 and DMEM (Life Technologies) in a 1:4 ratio with $0.8 \mathrm{mM}$ sodium pyruvate (Life Technologies), $3.4 \mathrm{~g} / \mathrm{l}$ sodium bicarbonate (SigmaAldrich), $15 \%$ fetal bovine serum (Thermo Scientific), $0.03 \mu \mathrm{g} / \mathrm{ml}$ Zinc sulfate (Fisher), $1.4 \mu \mathrm{g} / \mathrm{ml}$ vitamin B12 (Sigma-Aldrich), $2.5 \mathrm{ng} / \mathrm{ml}$ recombinant human hepatocyte growth factor (Millipore), $10 \mathrm{ng} / \mathrm{ml}$ basic fibroblast growth factor (BioPioneer), 0.02 M HEPES (Life Technologies), and $0.055 \mu \mathrm{g} / \mathrm{ml}$ dexamethasone (Sigma-Aldrich) at 
$37^{\circ} \mathrm{C}, 5 \% \mathrm{CO}_{2}$. The culture dish was coated with $0.1 \%$ gelatin (Sigma-Aldrich).

Myoblasts purity was determined by performing immunofluorescent staining using anti-human desmin (Dako) antibody. Myoblasts that exhibited greater than $70 \%$ desmin-positive cells were utilized for expression profiling. Immunostaining was conducted as previously described [60]. Briefly, the cells were fixed with $4 \%$ paraformaldehyde for 30 minutes, then blocked with $0.3 \%$ Triton X-100, $15 \%$ hose serum and $450 \mathrm{mM} \mathrm{NaCl}$ in phosphate buffer saline (PBS). Following blocking, fixed cells were incubated with anti-human desmin (Dako) for $4^{\circ} \mathrm{C}$ overnight. After washing 3 times, fixed cells were incubated with secondary antibody, DyLight 488-conjugated donkey anti-mouse IgG (Jackson ImmunoRessearch Laboratories). The slides were mounted using ProLong Gold Antifade Reagent with DAPI (Life Technologies) for further examination.

\section{Total RNA extraction and miRNA expression profiling}

To identify differentially expressed miRNA in FSHD primary myoblasts, we performed miRNA expression profiling using proliferating primary FSHD and control myoblasts ( $\mathrm{n}=3$, Additional file 1: Table S1). Total RNA with miRNA enrichment was extracted from cells using mirVana miRNA isolation kit (Life Technologies) according to manufacturer's protocol. Following RNA isolation, RNA quality and concentration were determined by gel electrophoresis and NanoDrop (Thermo Fisher Scientific), respectively. The miRNA profile of each myoblasts was determined using TaqMan Human MicroRNA Array v2.0 (Human Array A) (Life Technologies) according to manufacturer's protocol. Briefly, reverse transcription (RT) was performed with $100 \mathrm{ng}$ of total RNA, Multiplex RT Human primer pools, and TaqMan MicroRNA Reverse Transcriptase Kit (Life Technologies). Real-time PCR was performed with TaqMan Universal PCR Master Mix, No AmpErase UNG (Life Technologies) using the Applied Biosystems 7900HT System. Ct values of all miRNAs were determined using RQ Manager 1.2 (Life Technologies) with a threshold of 0.1 . Ct values were then imported into Partek Genomics Suite 6.5 and normalized to control, RNU48. ANOVA analysis was performed using Partek Genomics Suite 6.5 (Partek Incorporated, MO). No multiple testing corrections were performed.

\section{mRNA expression profiling and miRNA target search}

The total mRNA samples were expression-profiled using the Affymetrix Human Genome U133A plus 2.0 microarrays (Affymetrix) following the manufacture's protocol and as previously described $[17,61]$. Absolute analysis of the array data was performed using the MAS5 algorithm of the Affymetrix expression console. All genes with 10\% present calls were then imported into Partek Genomics Suite 6.5 for t-test analysis [62]. Targets of miRNA were predicted using Partek with the TargetScanHuman (release 5.1) database. The identified transcripts were further selected for those down-regulated in the FSHD myoblasts, considering that miRNAs generally down-regulate expression of the target genes.

\section{Quantitative reverse transcription polymerase chain reaction (qRT-PCR)}

Expression levels of miR-411 were analyzed by qRT-PCR using TaqMan MicroRNA assays according to the manufacturer's instructions. RNU48 served as an endogenous control (Life Technologies). Briefly, RT reactions were performed with $10 \mathrm{ng}$ of total RNA using TaqMan MicroRNA Reverse Transcriptase Kit (Life Technologies). Real-time PCR was performed using TaqMan Universal PCR Master Mix, No AmpErase UNG (Life Technologies) and Applied Biosystems 7900HT System. Relative fold changes were calculated using the comparative $C_{\mathrm{T}}$ Method ( $\Delta \Delta \mathrm{C}_{\mathrm{T}}$ Method) [63,64]. We chose RNU48 as the endogenous control because it demonstrated the most stable expression level among suggested internal control genes noted by Life Technologies.

Expression levels of Myod, myogenin, myosin heavy chain 1 (Myh1), and YY1 associated factor 2 (Yaf2) were determined using qRT-PCR as previously described [65]. 18s rRNA (Life Technologies) was used as the endogenous control. Briefly, RT reaction was performed with random hexamers and Super Script II (Life Technologies). Real-time PCR was performed with SYBR green Master Mix or TaqMan Universal PCR Master Mix (Life Technologies) using a final template concentration of $0.4 \mathrm{ng} / \mu \mathrm{l}$. Myod, myogenin and Myh1 primers were a gift from Dr. Tatiana V. Cohen [66]. The primer sequences were as follows: Myod, 5' - GGCTACGACACCGCCTACTA -3'; and $5^{\prime}$ - GCTCCACTATGCTGGACAGG - $3^{\prime}$. myogenin, 5'- GGGCAATGCACTGGAGTT -3'; and 5'- ATGGTT TCGTCTGGGAAGG - $3^{\prime}$. Myh1, $5^{\prime}$ - GCAAGAAGCAGA TCCAGAAAC - $3^{\prime}$; and 5'- CGGTCTTCCTCAGTTTGA TAAG - $3^{\prime}$. Yaf2, $5^{\prime}$ - ATCAGGGTTAGCGCTGTTGT - $3^{\prime}$; and $5^{\prime}$ - TGGCAAGTTCTTTCCTGCTT $-3^{\prime}$. All the $\mathrm{Ct}$ values were extracted with SDS (Life Technologies) and, after normalization using r18s, were converted into expression levels. Student t-tests were performed to determine the statistical significance of changes.

\section{In situ hybridization}

In situ hybridization was performed using $5^{\prime}$-digoxigenin (DIG) labeled miRCURY locked nucleic acid (LNA) detection probes, including hsa-miR-411 (38398-01), U6 (99002-01) and Scramble-miR (99004-01) (Exiqon) following the protocol from Exiqon and Roche with few modifications. Cultured cells were fixed with $4 \%$ 
paraformaldehyde (PFA)/PBS, rinsed with 100\% methanol, then rehydrated and acetylated. Cells were then prehybridized in hybridization buffer at $37^{\circ} \mathrm{C}$ for 1 hour [67]. The hybridization step was performed with $30 \mathrm{nM}$ heatdenatured LNA-probe at $37^{\circ} \mathrm{C}$ for overnight. After stringent washes with $50 \%$ formamide, $0.1 \%$ Tween-20, $2 \times$ SSC at $37^{\circ} \mathrm{C}$ and $0.2 \times \mathrm{SSC}$ at room temperature, the samples were incubated with blocking solution, and next with alkaline phosphatase (AP)-conjugated anti-DIG Fab fragment (Roche). The antibodies were detected with the 5-bromo 4-chloro-3-indolyl phosphate (BCIP)- nitroblue tetrazolium (NBT) colorimetric detection system incubating the slides in $0.35 \mathrm{mg} / \mathrm{ml} \mathrm{NBT}$ and $0.175 \mathrm{mg} / \mathrm{ml} \mathrm{BCIP}$ in $10 \%$ polyvinyl alcohol (PVA) and $1 \mathrm{mM}$ levamisole staining solution. The samples were mounted using ProLong Gold Antifade Reagent with DAPI (Life Technologies) for further examination.

\section{Immunoblotting}

Immunoblotting was performed as described previously [25]. Briefly, myoblasts were lysated with RIPA buffer (Sigma-Aldrich) on ice. Protein concentration was determined by DC protein assay (Bio-Rad), and $30 \mu \mathrm{g}$ of protein was loaded to $12 \%$ Bis-Tris NuPAGE Novex gels (Life Technologies) and then transferred to Hybond nitrocellulose membranes (Amersham Biosciences). After blocking, the membrane was incubated with rabbit polyclonal anti-YAF2 antibody $(1: 2,000)$ (Aviva) followed by horseradish peroxidase (HRP)-conjugated anti-rabbit antibodies (Amersham Biosciences). Chemiluminescent substrate (Pierce) was used to visualize the target proteins on blue light autorad film (BioExpress). Detection of the loading control, GAPDH (Santa Cruz Biotechnology), was similarly performed with 1:10,000 dilution of the mouse monoclonal primary antibody. The same blot was subsequently incubated with mouse monoclonal anti-human YY1 antibody (1:200) (Bio Matrix Research) to detect the YY1 protein followed by HRP-conjugated anti-mouse antibodies (Amersham Biosciences). Band density of the target protein was measured using a GS 800 Calibrated Densitometer (Bio-Rad) and image J [68] then normalized to the density of GAPDH. Student t-tests were performed to determine the statistical significance of changes. The experiments were performed in quadruplicate.

\section{Cell Transfection}

Cells were transfected with $30 \mathrm{mM}$ Ambion pre-miR -411 precursor oligos (Life Technologies) using Lipofectamine 2000 (Life Technologies) following the manufacture protocol. Briefly, $4 \times 10^{3} / \mathrm{cm}^{2} \mathrm{C}_{2} \mathrm{C}_{12}$ cells were plated in growth medium one day before the transfection. Cells were transfected when they reached $70 \%$ confluence. A final concentration of $30 \mathrm{nM}$ oligos was used for the transfection. Differentiation was induced 6 hours after the pre-miR-411 transfection.

\section{Results}

MiRNA-411 was differentially expressed in FSHD primary myoblasts

MiRNAs have been shown to be misregulated in FSHD and other muscular dystrophies and were proposed to be involved in the pathological mechanisms of muscular dystrophies. To identify miRNAs misregulated in proliferating FSHD myoblasts and their potential mRNA targets, we performed miRNA and mRNA expression profiling using total RNA samples isolated from 3 sets of proliferating primary myoblasts. Using TaqMan Human MicroRNA Arrays, we identified 8 miRNAs differentially expressed in FSHD myoblasts comparing to controls $(\mathrm{n}=3, \mathrm{p}<0.05)$ (Additional file 2: Table S2). To validate the findings, we performed qRT-PCR with an independent set of primary myoblasts $(n=4)$. Only miR-411 was validated using the second set of samples (2.1 fold, $\mathrm{p}<0.01$ ) (Figure 1A). To determine whether the same difference could be observed in immortalized FSHD myoblasts of which the control myoblasts were derived from an unaffected family member, we performed qRT-PCR and the results showed a similar difference in the immortalized FSHD myoblasts comparing to the control sample (2.7 fold, $\mathrm{p}<0.01, \mathrm{n}=4$ ) (Figure 1B).

The expression of miR-411 has been reported in brain, however the function and cellular localization of the miRNA is unknown. To determine the cellular localization of the miR-411 in myoblasts, we visualized miR-411 by in situ hybridization. The results showed that miR-411 was localized in the cytoplasm of the myoblasts. A subset
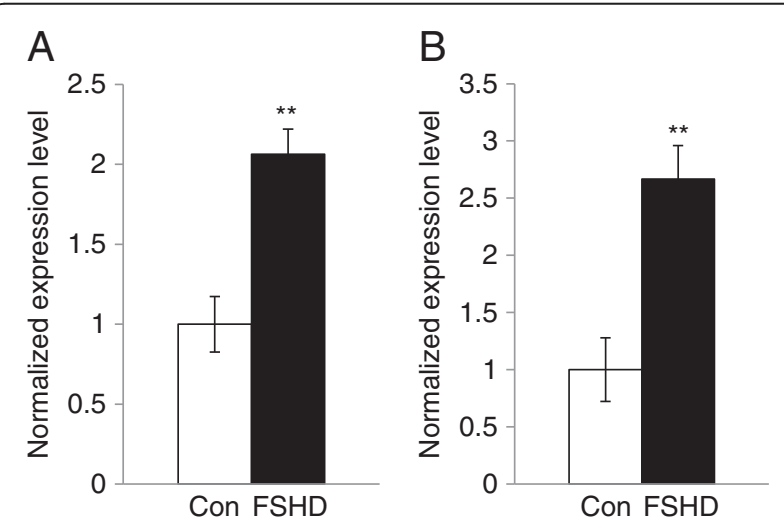

Figure 1 The up-regulation of miR-411 was validated in primary and immortalized FSHD myoblasts using qRT-PCR. MiR-411 expression was significantly higher in the proliferating primary myoblasts $(\mathbf{A})$ and immortalized myoblasts (B) of patients with FSHD ( $\mathrm{n}=4)$. White columns indicate control (Con) and black columns indicate FSHD myoblasts (FSHD). Error bars represent standard errors, and asterisks $\left(^{* *}\right)$ indicate $p<0.01$. 
of primary FSHD myoblasts showed stronger staining that can be visualized by the in situ hybridization (Figure 2B). The cells which expressed higher level of miR-411 were larger in size. The morphology is more similar to the FSHD cells showing necrotic phenotype reported previously $[32,69]$. The miR-411 expression in the control myoblasts as well as the negative probes in both the disease and control cells was not visible (Figure 2).

\section{Over-expression of miR-411 leads to down-regulation of YAF2, MYOD and myogenin}

To identify mRNA transcripts that can be potentially regulated by miR-411, mRNA profiles generated using the same total RNA samples used for miRNA profiling were analyzed to identify potential mRNA targets of miR-411. First, 1,502 mRNA transcripts were differentially expressed in the FSHD myoblasts comparing to the control samples during cell proliferation $(\mathrm{p}<0.05)$ (Additional file 3: Table S3). The miR-411 predicted targets were identified then compared to the mRNA transcript list using Partek Genomics Suite 6.5 to identify potential miRNA-mRNA interactions. Among the potential miR-411 targets, we further selected transcripts that were down-regulated in FSHD myoblasts based on the current knowledge that miRNAs negatively regulate target gene expression. Four candidate genes were identified, including YAF2 (-1.4 fold, $\mathrm{p}<0.05)$, calmodulinlike $4(C A L M L 4)(-1.8$ fold, $\mathrm{p}<0.05)$, mitogen-activated protein kinase kinase $1(M A P 2 K 1)(-1.2$ fold, $\mathrm{p}<0.05)$, and SH3 and multiple ankyrin repeat domains 2 (SHANK2) $(-1.9$ fold, $\mathrm{p}<0.05)$. Among the 4 genes, two genes, YAF2 and MAP2K1, are known to be involved in cell cycle regulation and early myogenesis. In addition, YAF2 negatively regulates myotube differentiation by inhibiting Yin Yang 1 (YY1) activity [70]. YY1 is a transcriptional repressor that inhibits muscle gene expression and myogenesis $[71,72]$. YAF2 interacts with YY1 and facilitates proteolytic cleavage of YY1 by m-calpain [70]

There are five human YAF2 transcript variants reported (GenBank). All five splice variants have one or two putative miR-411 binding site in their $3^{\prime}$ UTR (Additional file 4: Figure S1). Among these, YAF2 variant 2 has been cloned from the human muscle cDNA library as a protein which interacted with YY1 [70]. To determine if YAF2 expression is affected at the protein level in FSHD myoblasts, we performed immunoblotting and showed a 3.7 fold $(\mathrm{p}<0.01)$ down-regulation of YAF2 in FSHD immortalized myoblasts (Figure 3). The expression level of YY1 in the immortalized FHSD myoblasts was determined by immunoblotting. The result showed that YY1 was 8.3 fold $(\mathrm{p}<0.01)$ up-regulated in the FSHD myoblasts (Figure 3). To further determine whether miR-411 can regulate YAF2 and downstream pathways, $\mathrm{C}_{2} \mathrm{C}_{12}$ myoblasts were transfected with miR-411 precursor oligos, followed by cell differentiation for 5 days. The expression levels of miR-411, Yaf2 and myogenic markers, Myod, myogenin (Myog), and Myh1 were examined by qRT-PCR. The results showed that Yaf2 expression level was significantly down-regulated $(-4.5$ fold, $\mathrm{p}<0.05)$ by $\mathrm{miR}-411$ over-expression (Figure 4A). Interestingly, myogenic factors, Myod ( -1.4 fold, $\mathrm{p}<0.05)$ and Myog ( -2.1 fold, $\mathrm{p}<0.05)$ as well as a myotube differentiation marker, Myh1 ( -1.7 fold, $\mathrm{p}<0.05)$, were also significantly down-regulated by miR-411 over-expression (Figure 4B-D).

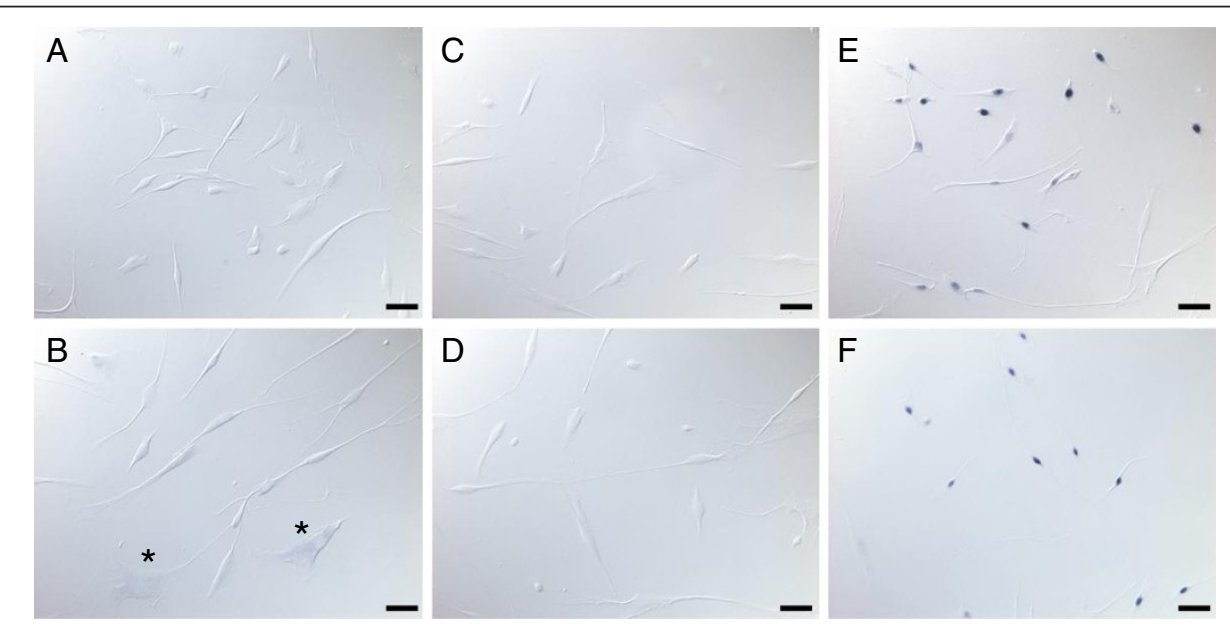

Figure 2 Cellular localization of miR-411 in FSHD myoblasts. The cellular localization of miR-411 was determined by in situ hybridization using LNA probes. While not seen in control myoblasts (A), the expression of miR-411 was visible in the cytoplasm of some FSHD myoblasts (B: marked by asterisks). The negative control using probes with scramble sequences did not generate any signal in control myoblasts (C) or FSHD myoblasts (D). In contrast, the positive control (U6 probe) showed nuclear staining in both control myoblasts (E) and FSHD myoblasts (F). The scale bar is $50 \mu \mathrm{m}$. 


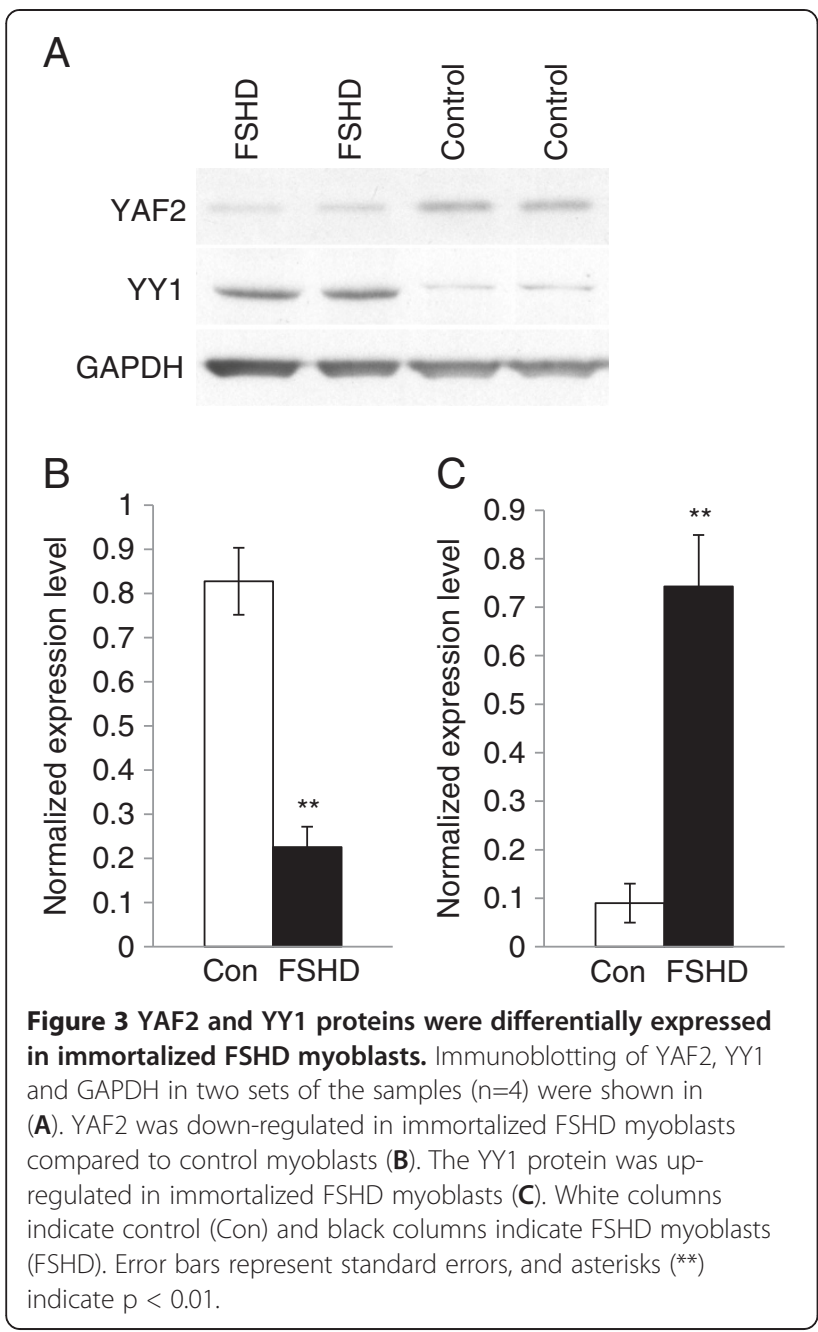

\section{Discussion}

To determine whether the differentially expressed miRNAs identified in our study overlap with changes identified in miRNAs in patient muscle biopsies [55], we compared our miRNA data to the previously published miRNA profiling study of 10 muscle disorders. In the study, expression of 62 out of 428 miRNAs examined was differentially expressed muscles of patients with FSHD. All miRNAs were up-regulated in the muscles while none was down-regulated. One miRNA, miR-517* was reported to be uniquely up-regulated in FSHD. We compared our myoblast miRNA profiling data to the study and found out that 5 out of the 8 miRNAs identified in our study were overlapped with the misregulated miRNAs in the previous study (Additional file 2: Table S2). Among the 5 miRNAs, miR-99b and miR-18a were also reported to be misregulated in FSHD biopsies. However, the directions of expression changes were the opposite in the two studies. While miR-517* was examined in our study, the expression was not detectable in
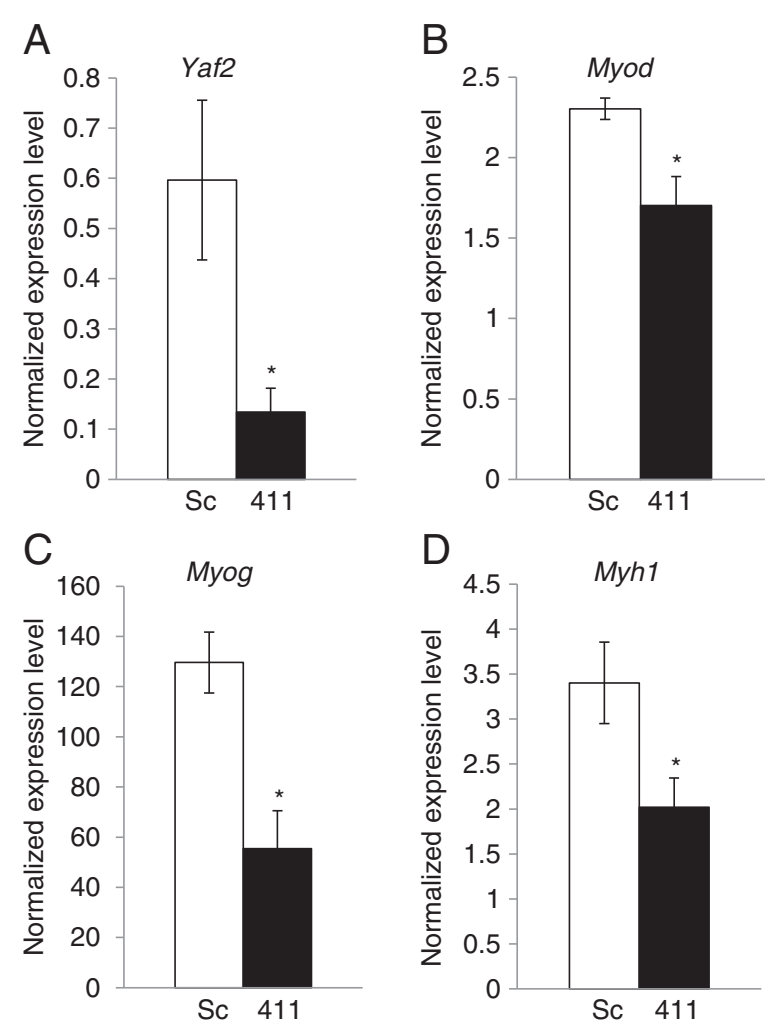

Figure 4 Over-expression of miR-411 reduced the expression level of differentiation markers in $C_{2} C_{12}$ murine myoblasts. Over-expression of miR-411 down-regulated expression of Yaf2 (A), Myod (B), myogenin (C), and Myh1 (D) as analyzed by real-time qRT-PCR ( $n=4)$. Each sample was transfected with miR-411 oligos (411) or negative oligo control (Sc). White columns indicate the control scramble-miRNA oligos (Sc) and black columns indicate the miR-411 oligos (411). Error bars represent standard errors, and an asterisk $\left(^{*}\right)$ indicates $p<0.05$.

either the FSHD and control myoblasts. The discrepancy may results from differences in sample type (muscle biopsies vs. primary myoblasts), disease stages, or platform used. It is not clear whether a probe detecting miR-411 was on the array used in the previous profiling study therefore it is not known whether miR-411 was changed in patients' muscle samples. While no study was conducted to investigate the function of miR-411, differential expression of miR-411 was reported in a miRNA profiling study of a mouse model of Duchenne muscular dystrophy known as the $m d x$ mouse model [54]. In this study, miR411 was reported to be down-regulated $(-1.8$ fold $)$ in the gastrocnimeous muscles of the $m d x$ mice. To date, it is not known whether the down-regulation of miR-411 contributes to the disease phenotype or participates in the muscle regeneration process in the $m d x$ mouse model. However, our data suggested that reduction of miR-411 may have a positive effect on muscle regeneration considering its potential to suppress factors that promote myoblast maturation. 
In this research, we showed that YAF2 was downregulated in FSHD myoblasts and is a potential target of miR-411. YAF2 is a $\mathrm{C}_{2} \mathrm{C}_{2}$-type zinc finger factor and an inhibitor of the YY1 protein, a known negative regulator of myogenesis [70]. YAF2 shows high similarity with YEAF1 and can be a part of Polycomb group (PcG) complexes [73,74]. YY1 is also a member of the PcG and has been shown to bind to the D4Z4 repeat with HMGB2 and nucleolin $[75,76]$. In myoblasts, YY1 inhibits differentiation through binding to the promoter regions of myofibrillar genes and the retinoblastoma gene $(\mathrm{Rb})$ which induces terminal exit from the cell cycle [77]. YY1 also inhibits miR-29 which is a positive regulator of myotube differentiation [78]. It has been shown that YY1 binds to the serum response factor (SRF) binding sequence, CArG box, in the regulatory region of the MYOD gene during muscle regeneration, which repressed the expression of MYOD [79]. SRF is a member of the MADS box transcription factor family and a positive regulator of myogenesis [80-83]. It is believed that YY1 inhibits myogenesis via competition for SRF binding sites and repressing expression of myogenic factors, such as MYOD. The expression level of YY1 protein in muscle cells is positively controlled by NF-kappa B which inhibits myogenesis, and negatively regulated by YAF2 [70,84]. YAF2 expression increases during muscle differentiation and directly binds to YY1 protein. The interaction between YAF2 and YY1 promotes proteolytic cleavage of YY1 by m-calpain, thus reducing YY1 protein levels in differentiating myofibers. Based on the findings, we hypothesized that the over-expression of miR-411 affects the expression of myogenic factors through the inhibition of YAF2 expression. The down-regulation of YAF2 might result in the accumulation of YY1 proteins therefore suppress MYOD and myogenin expression. Previous mRNA profiling studies examining patients' muscle biopsies showed that YY1 was up-regulated in FSHD biopsies [17]. In addition, YY1 was shown to be up-regulated in immortalized human myoblasts transfected with DUX4 expression vector [85]. In this study, we showed YY1 was up-regulated in FSHD myoblasts. Our findings suggested a potential regulatory mechanism of the YY1 up-regulation and the myogenesis defects observed in FSHD.

While some studies have reported that FSHD myoblasts exhibit a normal, healthy phenotype $[28,59,86]$, others reported an abnormal phenotype regarding their appearance and ability to differentiate [32,33,87]. Our results agree with the latter findings, as we observed some FSHD myoblasts with necrotic features as reported previously $[32,69]$. Interestingly, these cells also showed visible staining of miR-411 in their cytoplasm, suggesting the up-regulation of miR-411 may be involved at a later stage when the cells are further affected. Despite the phenotypic differences reported in the different groups, several expression profiling studies showed similar defects at the molecular level, such as in cell cycle regulation, early myogenesis, and oxidative stress responses [28,30-32]. MYOD is a master regulator of myogenesis and has been studied extensively [88,89]. MYOD is expressed in the early stages of myogenesis and induces myoblast differentiation through activation of downstream muscle-specific genes including myogenin, $M Y H 1$, as well as muscle-specific miRNAs, such as miR-1, miR133 and miR-206 [45,90,91]. MYOD also promotes cell cycle arrest to induce myoblast differentiation through activation of p21 and $\mathrm{Rb}[92,93]$. Overexpression of MYOD has been shown to convert 10T1/2 fibroblasts and other type of cell lines into myoblasts [94,95]. While MYOD is critical in activation of myogenesis, early up-regulation of myogenin, a downstream regulatory target of MYOD, can lead to premature myoblast differentiation, as seen in early myotube formation by FSHD myoblasts [96]. Expression profiling studies have supported this defect in FSHD myoblasts by showing up-regulation of MYOD, myogenin and other MYOD regulated genes in the proliferating cells $[29,31,96]$. Whether the up-regulation of miR-411 directly contributes to the disease pathogenesis, or is part of a compensatory response to suppress the prematurely activated MYOD program still needs to be further investigated.

\section{Conclusions}

In this study, we demonstrated that miR-411 was upregulated in both primary and immortalized FSHD myoblasts in comparison to control myoblasts. We also identified YAF2 as a potential regulatory target of miR-411 by analyzing the miRNA and mRNA expression profiling data generated from primary myoblasts. Over-expressing miR-411 in $\mathrm{C}_{2} \mathrm{C}_{12}$ cells leads to down-regulation of Myod, myogenin, and Myh1. Based on previous findings as well as our own observations, we propose a potential model of how up-regulation of miR-411 can be involved in the myogenic defect observed in FSHD myoblasts. Starting with the up-regulation of miR-411, YAF2 is suppressed, which will then positively regulate YY1. Up-regulation of YY1 suppresses myogenic factors including MYOD and myogenin, which directly affect myogenesis. Alternatively, the up-regulation of miR-411 may be a compensatory mechanism to the hypothesized premature activation of the MYOD program. While each specific regulatory relationship needs to be further investigated, our findings demonstrated a potential role of miR-411 in regulating myogenesis, and provides a novel molecular regulatory mechanism that may be involved in FSHD pathogenesis. In addition, miRNAs circulating in the blood have been acknowledged as readily accessible disease markers. Thus, 
miR-411 may be a potential candidate as a biomarker in FSHD studies.

\section{Additional files}

Additional file 1: Table S1. Human primary myoblasts used for miRNA and mRNA profiling (the top 6 samples) and validation (the bottom 8 samples).

Additional file 2: Table S2. miRNAs differentially expressed in proliferating FSHD myoblasts $(p<0.05)$.

Additional file 3: Table S3. mRNAs differentially expressed in proliferating FSHD myoblasts $(p<0.05)$.

Additional file 4: Figure S1. Putative miR-411 binding sites in the $3^{\prime}$ UTR of 5 splice variants of YAF2. The seed region of miR-411 is underlined. The complimentary bases are highlighted in yellow. The variant 2 has been reported to be expressed in skeletal muscles.

\section{Abbreviations}

(FSHD): Facioscapulohumeral muscular dystrophy; (DUX4): double homeobox protein 4; (fl-DUX4): full-length DUX4 transcript; (miRNA): microRNA (pri-RNA): primary-miRNA; (RISC): RNA-induced silencing complex; (Mef2): myocyte enhancing factor 2; (PBS): phosphate buffer saline; (RT): reverse transcription; (qRT-PCR): quantitative reverse transcription polymerase chain reaction; (Myh1): myosin heavy chain 1; (YAF2): YY1 associated factor 2; (DIG): 5'-digoxigenin; (LNA): locked nucleic acid; (PFA): paraformaldehyde; (AP): alkaline phosphatase; (BCIP): 5-bromo 4-chloro -3-indolyl phosphate; (NBT): nitroblue tetrazolium; (PVA): polyvinyl alcohol; (HRP): horseradish peroxidase; (CALML4): calmodulin-like 4; (MAP2K1): mitogen-activated protein kinase kinase 1; (SHANK2): SH3 and multiple ankyrin repeat domains 2; (YY1): Yin Yang 1; (Myog): myogenin; (PcG): Polycomb group; (Rb): retinoblastoma gene; (SRF): serum response factor.

\section{Competing interests}

The authors declare no conflicts of interests.

\section{Authors' contributions}

PS and MCW provided the primary myoblasts and participated in manuscript preparation. $\mathrm{NH}$ performed the experiments and prepared the manuscript. Y-WC designed and supervised the experiments and prepared the manuscript. All authors read and approved the final manuscript.

\section{Acknowledgements}

Research reported in this publication was supported by the NIH/NIAMS under Award Number 1R01AR052027. The content is solely the responsibility of the authors and does not necessarily represent the official views of the National Institutes of Health. NH is supported by NIH/NIAMS1R01AR052027. Y-WC is supported by NIH/NIAMS1R01AR052027, NIH/NICHD1R24HD050846 and DOD DOD W81XWH-10-1-0659. We thank the Wellstone Muscular Dystrophy Center at the Boston Biomedical Research Institute for providing the immortalized myoblasts. We thank Muscle Tissue Culture Collection MTCC for providing the primary myoblasts samples. The Muscle Tissue Culture Collection is part of the German network on muscular dystrophies (MD-NET, service structure S1, 01GM0601) and the German network for mitochondrial disorders (mito-NET, project D2, 01GM0862) funded by the German ministry of education and research (BMBF, Bonn, Germany). The Muscle Tissue Culture Collection is a partner of EuroBioBank (www. eurobiobank.org) and TREAT-NMD (www.treat-nmd.eu).

\section{Author details}

'Center for Genetic Medicine Research, Children's Research Institute, Washington, DC, USA. ${ }^{2}$ Friedrich-Baur-Institute, Department of Neurology, Ludwig-Maximilians-University of Munich, Munich, Germany. ${ }^{3}$ Department of Integrative Systems Biology and Department of Pediatrics, George Washington University, Washington, DC, USA. ${ }^{4}$ Center for Genetic Medicine Research, Children's National Medical Center, 111 Michigan Avenue, NW, Washington, DC 20010, USA.
Received: 16 January 2013 Accepted: 22 March 2013

Published: 5 April 2013

\section{References}

1. Padberg GW, Frants RR, Brouwer OF, Wijmenga C, Bakker E, Sandkuij LA: Facioscapulohumeral muscular dystrophy in the Dutch population. Muscle Nerve 1995, 2:581-S84.

2. Zatz M, Marie SK, Passos-Bueno MR, Vainzof $M$, Campiotto $S$, Cerqueira A, Wijmenga C, Padberg G, Frants R: High proportion of new mutations and possible anticipation in Brazilian facioscapulohumeral muscular dystrophy families. Am J Hum Genet 1995, 56:99-105.

3. Lunt PW, Compston DA, Harper PS: Estimation of age dependent penetrance in facioscapulohumeral muscular dystrophy by minimising ascertainment bias. J Med Genet 1989, 26:755-760

4. Tawil R, Figlewicz DA, Griggs RC, Weiffenbach B: Facioscapulohumeral dystrophy: a distinct regional myopathy with a novel molecular pathogenesis. FSH Consortium. Ann Neurol 1998, 43:279-282.

5. Padberg GW, Lunt PW, Koch M, Fardeau M: Diagnostic criteria for facioscapulohumeral muscular dystrophy. Neuromuscul Disord 1991, 1:231-234.

6. Wijmenga C, Hewitt JE, Sandkuijl LA, Clark LN, Wright TJ, Dauwerse HG, Gruter AM, Hofker MH, Moerer P, Williamson R, et al: Chromosome 4q DNA rearrangements associated with facioscapulohumeral muscular dystrophy. Nat Genet 1992, 2:26-30

7. Padberg GW: Facioscapulohumeral disease. University of Leiden: Doctral; 1982.

8. Padberg GW: Facioscapulohumeral Muscular Dystrophy: a Clinician's Experience. In Facioscapulohumeral muscular dystrophy. Edited by Upadhyaya D, Cooper DN. Clinical Medicine and Molecular Cell Biology, Garland Science/BIOS Scientific Publishers; 2004:41-54.

9. Arahata K, Ishihara T, Fukunaga H, Orimo S, Lee JH, Goto K, Nonaka I: Inflammatory response in facioscapulohumeral muscular dystrophy (FSHD): immunocytochemical and genetic analyses. Muscle Nerve 1995, 2:S56-S66.

10. Padberg G, Adams C: Facioscapulohumeral muscular dystrophy. In Neurogenetics. Edited by Pulst S-M. Oxford, UK: Oxford University Press; 2000:105-116

11. Padberg GW, Brouwer OF, de Keizer RJ, Dijkman G, Wijmenga C, Grote JJ, Frants RR: On the significance of retinal vascular disease and hearing loss in facioscapulohumeral muscular dystrophy. Muscle Nerve 1995, 2:S73-S80.

12. Tupler R, Berardinelli A, Barbierato L, Frants R, Hewitt JE, Lanzi G, Maraschio $P$, Tiepolo L: Monosomy of distal $4 q$ does not cause facioscapulohumeral muscular dystrophy. J Med Genet 1996, 33:366-370.

13. van der Maarel SM, Frants RR, Padberg GW: Facioscapulohumeral muscular dystrophy. Biochim Biophys Acta 2007, 1772:186-194.

14. van Deutekom JC, Wijmenga C, van Tienhoven EA, Gruter AM, Hewitt JE, Padberg GW, van Ommen GJ, Hofker MH, Frants RR: FSHD associated DNA rearrangements are due to deletions of integral copies of a $3.2 \mathrm{~kb}$ tandemly repeated unit. Hum Mol Genet 1993, 2:2037-2042.

15. Bengtsson U, Altherr MR, Wasmuth JJ, Winokur ST: High resolution fluorescence in situ hybridization to linearly extended DNA visually maps a tandem repeat associated with facioscapulohumeral muscular dystrophy immediately adjacent to the telomere of 4q. Hum Mol Genet 1994, 3:1801-1805.

16. Hewitt JE, Lyle R, Clark LN, Valleley EM, Wright TJ, Wijmenga C, van Deutekom JC, Francis F, Sharpe PT, Hofker M, et al: Analysis of the tandem repeat locus D4Z4 associated with facioscapulohumeral muscular dystrophy. Hum Mol Genet 1994, 3:1287-1295.

17. Dixit M, Ansseau E, Tassin A, Winokur S, Shi R, Qian H, Sauvage S, Matteotti C, van Acker AM, Leo O, et al: DUX4, a candidate gene of facioscapulohumeral muscular dystrophy, encodes a transcriptional activator of PITX1. Proc Natl Acad Sci U S A 2007, 104:18157-18162.

18. Snider L, Geng LN, Lemmers RJ, Kyba M, Ware CB, Nelson AM, Tawil R, Filippova GN, van der Maarel SM, Tapscott SJ, Miller DG: Facioscapulohumeral dystrophy: incomplete suppression of a retrotransposed gene. PLoS Genet 2010, 6:e1001181.

19. Snider L, Asawachaicharn A, Tyler AE, Geng LN, Petek LM, Maves L, Miller DG, Lemmers RJ, Winokur ST, Tawil R, et al: RNA transcripts, miRNA-sized fragments and proteins produced from D4Z4 units: new candidates for the pathophysiology of facioscapulohumeral dystrophy. Hum Mol Genet 2009, 18:2414-2430. 
20. Bosnakovski D, Xu Z, Gang EJ, Galindo CL, Liu M, Simsek T, Garner HR, Agha-Mohammadi S, Tassin A, Coppee F, et al: An isogenetic myoblast expression screen identifies DUX4-mediated FSHD-associated molecular pathologies. EMBO J 2008, 27:2766-2779.

21. Kowaljow V, Marcowycz A, Ansseau E, Conde CB, Sauvage S, Matteotti C, Arias C, Corona ED, Nunez NG, Leo O, et al: The DUX4 gene at the FSHD1A locus encodes a pro-apoptotic protein. Neuromuscul Disord 2007, 17:611-623.

22. Wuebbles RD, Long SW, Hanel ML, Jones PL: Testing the effects of FSHD candidate gene expression in vertebrate muscle development. Int J Clin Exp Pathol 2010, 3:386-400.

23. Wallace LM, Garwick SE, Mei W, Belayew A, Coppee F, Ladner K, Guttridge D, Yang J, Harper SQ: DUX4, a candidate gene for facioscapulohumeral muscular dystrophy, causes p53-dependent myopathy in vivo. Ann Neurol 2010

24. Vanderplanck C, Ansseau E, Charron S, Stricwant N, Tassin A, Laoudj-Chenivesse D, Wilton SD, Coppee F, Belayew A: The FSHD atrophic myotube phenotype is caused by DUX4 expression. PLoS One 2011, 6:e26820.

25. Pandey SN, Cabotage J, Shi R, Dixit M, Sutherland M, Liu J, Muger S, Harper SQ, Nagaraju K, Chen YW: Conditional over-expression of PITX1 causes skeletal muscle dystrophy in mice. Biol Open 2012, 1:629-639.

26. van Overveld PG, Lemmers RJ, Sandkuijl LA, Enthoven L, Winokur ST, Bakels F, Padberg GW, van Ommen GJ, Frants RR, van der Maarel SM: Hypomethylation of D4Z4 in 4q-linked and non-4q-linked facioscapulohumeral muscular dystrophy. Nat Genet 2003, 35:315-317.

27. Lemmers RJ, van der Vliet PJ, Klooster R, Sacconi S, Camano P, Dauwerse JG, Snider L, Straasheijm KR, Jan Van Ommen G, Padberg GW, et al: A Unifying Genetic Model for Facioscapulohumeral Muscular Dystrophy. Science 2010, 329:1650-1653.

28. Tsumagari K, Chang SC, Lacey M, Baribault C, Chittur SV, Sowden J, Tawil R, Crawford GE, Ehrlich M: Gene expression during normal and FSHD myogenesis. BMC Med Genomics 2011, 4:67.

29. Winokur ST, Chen YW, Masny PS, Martin JH, Ehmsen JT, Tapscott SJ, van der Maarel SM, Hayashi Y, Flanigan KM: Expression profiling of FSHD muscle supports a defect in specific stages of myogenic differentiation. Hum Mol Genet 2003, 12:2895-2907.

30. Celegato B, Capitanio D, Pescatori M, Romualdi C, Pacchioni B, Cagnin S, Vigano A, Colantoni L, Begum S, Ricci E, et al: Parallel protein and transcript profiles of FSHD patient muscles correlate to the D4Z4 arrangement and reveal a common impairment of slow to fast fibre differentiation and a general deregulation of MyoD-dependent genes. Proteomics 2006, 6:5303-5321.

31. Cheli S, Francois S, Bodega B, Ferrari F, Tenedini E, Roncaglia E, Ferrari S, Ginelli E, Meneveri R: Expression profiling of FSHD-1 and FSHD-2 cells during myogenic differentiation evidences common and distinctive gene dysregulation patterns. PLoS One 2011, 6:e20966.

32. Winokur ST, Barrett K, Martin JH, Forrester JR, Simon M, Tawil R, Chung SA, Masny PS, Figlewicz DA: Facioscapulohumeral muscular dystrophy (FSHD) myoblasts demonstrate increased susceptibility to oxidative stress. Neuromuscul Disord 2003, 13:322-333.

33. Barro M, Carnac G, Flavier S, Mercier J, Vassetzky Y, Laoudj-Chenivesse D: Myoblasts from affected and non-affected FSHD muscles exhibit morphological differentiation defects. J Cell Mol Med 2010, 14:275-289.

34. Tawil R: Facioscapulohumeral muscular dystrophy. Neurotherapeutics 2008, 5:601-606

35. Sayed D, Abdellatif M: MicroRNAs in development and disease. Physiol Rev 2011, 91:827-887.

36. Winter J, Jung S, Keller S, Gregory RI, Diederichs S: Many roads to maturity: microRNA biogenesis pathways and their regulation. Nat Cell Biol 2009, 11:228-234

37. Lee Y, Ahn C, Han J, Choi H, Kim J, Yim J, Lee J, Provost P, Radmark O, Kim $\mathrm{S}, \mathrm{Kim}$ VN: The nuclear RNase III Drosha initiates microRNA processing Nature 2003, 425:415-419.

38. Lund E, Guttinger S, Calado A, Dahlberg JE, Kutay U: Nuclear export of microRNA precursors. Science 2004, 303:95-98.

39. Schwarz DS, Hutvagner G, Haley B, Zamore PD: Evidence that siRNAs function as guides, not primers, in the Drosophila and human RNAi pathways. Mol Cell 2002, 10:537-548.

40. Guller I, Russell AP: MicroRNAs in skeletal muscle: their role and regulation in development, disease and function. J Physiol, 588:4075-4087.

41. Bartel DP: MicroRNAs: genomics, biogenesis, mechanism, and function. Cell 2004, 116:281-297.
42. Stefani G, Slack FJ: Small non-coding RNAs in animal development. Nat Rev Mol Cell Biol 2008, 9:219-230.

43. Valencia-Sanchez MA, Liu J, Hannon GJ, Parker R: Control of translation and mRNA degradation by miRNAs and siRNAs. Genes Dev 2006, 20:515-524.

44. Cardinali B, Castellani L, Fasanaro P, Basso A, Alema S, Martelli F, Falcone G: Microrna-221 and microrna-222 modulate differentiation and maturation of skeletal muscle cells. PLoS One 2009, 4:e7607.

45. Rao PK, Kumar RM, Farkhondeh M, Baskerville S, Lodish HF: Myogenic factors that regulate expression of muscle-specific microRNAs. Proc Natl Acad Sci U S A 2006, 103:8721-8726.

46. Chen JF, Mandel EM, Thomson JM, Wu Q, Callis TE, Hammond SM, Conlon FL, Wang DZ: The role of microRNA-1 and microRNA-133 in skeletal muscle proliferation and differentiation. Nat Genet 2006 , 38:228-233.

47. Chen JF, Tao Y, Li J, Deng Z, Yan Z, Xiao X, Wang DZ: microRNA-1 and microRNA-206 regulate skeletal muscle satellite cell proliferation and differentiation by repressing Pax7. J Cell Biol 2010, 190:867-879.

48. Naguibneva I, Ameyar-Zazoua M, Polesskaya A, Ait-Si-Ali S, Groisman R, Souidi M, Cuvellier S, Harel-Bellan A: The microRNA miR-181 targets the homeobox protein Hox-A11 during mammalian myoblast differentiation. Nat Cell Biol 2006, 8:278-284.

49. Liu J, Luo XJ, Xiong AW, Zhang ZD, Yue S, Zhu MS, Cheng SY: MicroRNA-214 promotes myogenic differentiation by facilitating exit from mitosis via down-regulation of proto-oncogene N-ras. J Biol Chem, 285:26599-26607.

50. Sun $Q$, Zhang Y, Yang G, Chen X, Cao G, Wang J, Sun Y, Zhang P, Fan M, Shao N, Yang $X$ : Transforming growth factor-beta-regulated miR-24 promotes skeletal muscle differentiation. Nucleic Acids Res 2008, 36:2690-2699.

51. Flynt AS, Li N, Thatcher EJ, Solnica-Krezel L, Patton JG: Zebrafish miR-214 modulates Hedgehog signaling to specify muscle cell fate. Nat Genet 2007, 39:259-263.

52. McCarthy JJ, Esser KA, Andrade FH: MicroRNA-206 is overexpressed in the diaphragm but not the hindlimb muscle of $m d x$ mouse. Am J Physiol Cell Physiol 2007, 293:C451-457.

53. Gambardella S, Rinaldi F, Lepore SM, Viola A, Loro E, Angelini C, Vergani L, Novelli G, Botta A: Overexpression of microRNA-206 in the skeletal muscle from myotonic dystrophy type 1 patients. J Trans/ Med, 8:48.

54. Cacchiarelli D, Martone J, Girardi E, Cesana M, Incitti T, Morlando M, Nicoletti C, Santini T, Sthandier O, Barberi L, et al: MicroRNAs involved in molecular circuitries relevant for the Duchenne muscular dystrophy pathogenesis are controlled by the dystrophin/nNOS pathway. Cell Metab 2010, 12:341-351.

55. Eisenberg I, Eran A, Nishino I, Moggio M, Lamperti C, Amato AA, Lidov HG, Kang PB, North KN, Mitrani-Rosenbaum S, et al: Distinctive patterns of microRNA expression in primary muscular disorders. Proc Natl Acad Sci US A 2007, 104:17016-17021.

56. Glazov EA, McWilliam S, Barris WC, Dalrymple BP: Origin, evolution, and biological role of miRNA cluster in DLK-DIO3 genomic region in placental mammals. Mol Biol Evol 2008, 25:939-948.

57. Fiore R, Khudayberdiev S, Christensen M, Siegel G, Flavell SW, Kim TK, Greenberg ME, Schratt G: Mef2-mediated transcription of the miR379-410 cluster regulates activity-dependent dendritogenesis by fine-tuning Pumilio2 protein levels. EMBO J 2009, 28:697-710.

58. Stadler G, Chen JC, Wagner K, Robin JD, Shay JW, Emerson CP Jr, Wright WE: Establishment of clonal myogenic cell lines from severely affected dystrophic muscles - CDK4 maintains the myogenic population. Skelet Muscle 2011, 1:12

59. Homma S, Chen JC, Rahimov F, Beermann ML, Hanger K, Bibat GM, Wagner KR, Kunkel LM, Emerson CP Jr, Miller JB: A unique library of myogenic cells from facioscapulohumeral muscular dystrophy subjects and unaffected relatives: family, disease and cell function. Eur J Hum Genet 2012, 20:404-410.

60. Chen YW, Nader GA, Baar KR, Fedele MJ, Hoffman EP, Esser KA: Response of rat muscle to acute resistance exercise defined by transcriptional and translational profiling. J Physiol 2002, 545:27-41.

61. Chen YW, Zhao P, Borup R, Hoffman EP: Expression profiling in the muscular dystrophies: identification of novel aspects of molecular pathophysiology. J Cell Biol 2000, 151:1321-1336.

62. Thompson WA Jr: The Problem of Negative Estimates of Variance Components. Ann Math Statist 1962, 33:273-289.

63. Bookout AL, Mangelsdorf DJ: Quantitative real-time PCR protocol for analysis of nuclear receptor signaling pathways. Nucl Recept Signal 2003, 1:e012. 
64. Guide to Performing Relative Quantitation of Gene Expression Using RealTime Quantitative PCR Applied Biosystems.

65. Chen YW, Hubal MJ, Hoffman EP, Thompson PD, Clarkson PM: Molecular responses of human muscle to eccentric exercise. J Appl Physiol 2003, 95:2485-2494

66. Duddy WJ, Cohen T, Duguez S, Partridge TA: The isolated muscle fibre as a model of disuse atrophy: characterization using PhAct, a method to quantify f-actin. Exp Cell Res 2011, 317:1979-1993.

67. Wilkinson DG: in situ hybridization: a practical approach. Oxford University Press; 1992.

68. Schneider CA, Rasband WS, Eliceiri KW: NIH Image to ImageJ: 25 years of image analysis. Nat Methods 2012, 9:671-675.

69. Rijkers $T$, Deidda G, van Koningsbruggen S, van Geel M, Lemmers RJ, van Deutekom JC, Figlewicz D, Hewitt JE, Padberg GW, Frants RR, van der Maarel SM: FRG2, an FSHD candidate gene, is transcriptionally upregulated in differentiating primary myoblast cultures of FSHD patients. J Med Genet 2004, 41:826-836.

70. Kalenik JL, Chen D, Bradley ME, Chen SJ, Lee TC: Yeast two-hybrid cloning of a novel zinc finger protein that interacts with the multifunctional transcription factor YY1. Nucleic Acids Res 1997, 25:843-849.

71. Gualberto A, LePage D, Pons G, Mader SL, Park K, Atchison ML, Walsh K: Functional antagonism between $\mathrm{YY} 1$ and the serum response factor. Mol Cell Biol 1992, 12:4209-4214.

72. Lee TC, Chow KL, Fang P, Schwartz RJ: Activation of skeletal alpha-actin gene transcription: the cooperative formation of serum response factor-binding complexes over positive cis-acting promoter serum response elements displaces a negative-acting nuclear factor enriched in replicating myoblasts and nonmyogenic cells. Mol Cell Biol 1991, 11:5090-5100.

73. Kaneko T, Miyagishima H, Hasegawa T, Mizutani-Koseki $Y$, Isono K, Koseki H: The mouse YAF2 gene generates two distinct transcripts and is expressed in pre-and postimplantation embryos. Gene 2003, 315:183-192.

74. Sawa C, Yoshikawa T, Matsuda-Suzuki F, Delehouzee S, Goto M, Watanabe H, Sawada J, Kataoka K, Handa H: YEAF1/RYBP and YAF-2 are functionally distinct members of a cofactor family for the YY1 and E4TF1/hGABP transcription factors. J Biol Chem 2002, 277:22484-22490.

75. Sparmann A, van Lohuizen M: Polycomb silencers control cell fate, development and cancer. Nat Rev Cancer 2006, 6:846-856.

76. Gabellini D, Green MR, Tupler R: Inappropriate gene activation in FSHD: a repressor complex binds a chromosomal repeat deleted in dystrophic muscle. Cell 2002, 110:339-348.

77. Delehouzee S, Yoshikawa T, Sawa C, Sawada J, Ito T, Omori M, Wada T, Yamaguchi $Y$, Kabe $Y$, Handa H: GABP, HCF-1 and YY1 are involved in Rb gene expression during myogenesis. Genes Cells 2005, 10:717-731.

78. Wang H, Garzon R, Sun H, Ladner KJ, Singh R, Dahlman J, Cheng A, Hall BM, Qualman SJ, Chandler DS, et al: NF-kappaB-YY1-miR-29 regulatory circuitry in skeletal myogenesis and rhabdomyosarcoma. Cancer Cell 2008, 14:369-381.

79. L'Honore A, Lamb NJ, Vandromme M, Turowski P, Carnac G, Fernandez A: MyoD distal regulatory region contains an SRF binding CArG element required for MyoD expression in skeletal myoblasts and during muscle regeneration. Mol Biol Cell 2003, 14:2151-2162.

80. Treisman R: The serum response element. Trends Biochem Sci 1992, 17:423-426.

81. Vandromme M, Gauthier-Rouviere C, Carnac G, Lamb N, Fernandez A: Serum response factor $\mathrm{p} 67 \mathrm{SRF}$ is expressed and required during myogenic differentiation of both mouse C2 and rat L6 muscle cell lines. J Cell Biol 1992, 118:1489-1500.

82. Gauthier-Rouviere C, Vandromme M, Tuil D, Lautredou N, Morris M, Soulez M, Kahn A, Fernandez A, Lamb N: Expression and activity of serum response factor is required for expression of the muscle-determining factor MyoD in both dividing and differentiating mouse $\mathrm{C} 2 \mathrm{C} 12$ myoblasts. Mol Biol Cell 1996, 7:719-729.

83. Soulez M, Rouviere CG, Chafey P, Hentzen D, Vandromme M, Lautredou N, Lamb N, Kahn A, Tuil D: Growth and differentiation of C2 myogenic cells are dependent on serum response factor. Mol Cell Biol 1996, 16:6065-6074.

84. Wang H, Hertlein E, Bakkar N, Sun H, Acharyya S, Wang J, Carathers M, Davuluri R, Guttridge DC: NF-kappaB regulation of YY1 inhibits skeletal myogenesis through transcriptional silencing of myofibrillar genes. $\mathrm{Mol}$ Cell Biol 2007, 27:4374-4387.

85. Geng LN, Yao Z, Snider L, Fong AP, Cech JN, Young JM, van der Maarel SM, Ruzzo WL, Gentleman RC, Tawil R, Tapscott SJ: DUX4 activates germline genes, retroelements, and immune mediators: implications for facioscapulohumeral dystrophy. Dev Cell 2012, 22:38-51.

86. Vilquin JT, Marolleau JP, Sacconi S, Garcin I, Lacassagne MN, Robert I, Ternaux B, Bouazza B, Larghero J, Desnuelle C: Normal growth and regenerating ability of myoblasts from unaffected muscles of facioscapulohumeral muscular dystrophy patients. Gene Ther 2005, 12:1651-1662

87. Morosetti R, Mirabella M, Gliubizzi C, Broccolini A, Sancricca C, Pescatori M, Gidaro T, Tasca G, Frusciante R, Tonali PA, et al: Isolation and characterization of mesoangioblasts from facioscapulohumeral muscular dystrophy muscle biopsies. Stem Cells 2007, 25:3173-3182.

88. Aziz A, Liu QC, Dilworth FJ: Regulating a master regulator: establishing tissue-specific gene expression in skeletal muscle. Epigenetics 2010, 5:691-695

89. Rudnicki MA, Schnegelsberg PN, Stead RH, Braun T, Arnold HH, Jaenisch R: MyoD or Myf-5 is required for the formation of skeletal muscle. Cell 1993, 75:1351-1359.

90. Cao Y, Yao Z, Sarkar D, Lawrence M, Sanchez GJ, Parker MH, MacQuarrie KL, Davison J, Morgan MT, Ruzzo WL, et al: Genome-wide MyoD binding in skeletal muscle cells: a potential for broad cellular reprogramming. Dev Cell 2010, 18:662-674.

91. Bergstrom DA, Penn BH, Strand A, Perry RL, Rudnicki MA, Tapscott SJ: Promoter-specific regulation of MyoD binding and signal transduction cooperate to pattern gene expression. Mol Cell 2002, 9:587-600.

92. Martelli F, Cenciarelli C, Santarelli G, Polikar B, Felsani A, Caruso M: MyoD induces retinoblastoma gene expression during myogenic differentiation. Oncogene 1994, 9:3579-3590.

93. Halevy O, Novitch BG, Spicer DB, Skapek SX, Rhee J, Hannon GJ, Beach D, Lassar AB: Correlation of terminal cell cycle arrest of skeletal muscle with induction of p21 by MyoD. Science 1995, 267:1018-1021.

94. Lassar $A B$, Paterson BM, Weintraub $H$ : Transfection of a DNA locus that mediates the conversion of 10T1/2 fibroblasts to myoblasts. Cell 1986 47:649-656.

95. Davis RL, Weintraub $H$, Lassar AB: Expression of a single transfected cDNA converts fibroblasts to myoblasts. Cell 1987, 51:987-1000.

96. Krom YD, Dumonceaux J, Mamchaoui K, den Hamer B, Mariot V, Negroni E, Geng LN, Martin N, Tawil R, Tapscott SJ, et al: Generation of isogenic D4Z4 contracted and noncontracted immortal muscle cell clones from a mosaic patient: a cellular model for FSHD. Am J Pathol 2012, 181:1387-1401.

doi:10.1186/1750-1172-8-55

Cite this article as: Harafuji et al:: miR-411 is up-regulated in FSHD myoblasts and suppresses myogenic factors. Orphanet Journal of Rare Diseases 2013 8:55.

\section{Submit your next manuscript to BioMed Central and take full advantage of:}

- Convenient online submission

- Thorough peer review

- No space constraints or color figure charges

- Immediate publication on acceptance

- Inclusion in PubMed, CAS, Scopus and Google Scholar

- Research which is freely available for redistribution 